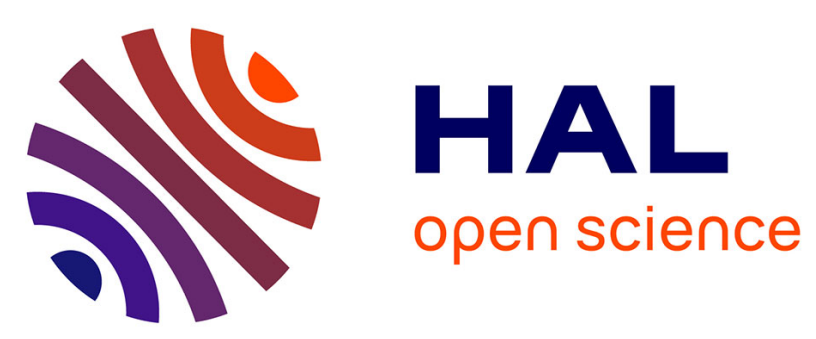

\title{
Hydration of the sulfate dianion in size-selected water clusters: From SO42-(H2O)9 to SO42-(H2O)13
}

\author{
Florian Thaunay, Ayah A Hassan, Richard J Cooper, Evan R Williams, \\ Carine Clavaguera, Gilles Ohanessian
}

\section{- To cite this version:}

Florian Thaunay, Ayah A Hassan, Richard J Cooper, Evan R Williams, Carine Clavaguera, et al.. Hydration of the sulfate dianion in size-selected water clusters: From SO42-(H2O) 9 to SO42-(H2O)13. International Journal of Mass Spectrometry, 2017, 418, pp.15-23. 10.1016/j.ijms.2017.01.005 . hal01999955

\section{HAL Id: hal-01999955 \\ https://hal.science/hal-01999955}

Submitted on 14 Jan 2020

HAL is a multi-disciplinary open access archive for the deposit and dissemination of scientific research documents, whether they are published or not. The documents may come from teaching and research institutions in France or abroad, or from public or private research centers.
L'archive ouverte pluridisciplinaire HAL, est destinée au dépôt et à la diffusion de documents scientifiques de niveau recherche, publiés ou non, émanant des établissements d'enseignement et de recherche français ou étrangers, des laboratoires publics ou privés. 


\title{
Hydration of the sulfate dianion in size-selected water clusters: From $\mathrm{SO}_{4}{ }^{2-}\left(\mathrm{H}_{2} \mathrm{O}\right)_{9}$ to $\mathrm{SO}_{4}{ }^{2-}\left(\mathrm{H}_{2} \mathrm{O}\right)_{13}$
}

\author{
Florian Thaunay ${ }^{\mathrm{a}}$, Ayah A. Hassan ${ }^{\mathrm{a}}$, Richard J. Cooper ${ }^{\mathrm{b}}$, Evan R. Williams ${ }^{\mathrm{b}, *}$, \\ Carine Clavaguéra ${ }^{a}$, Gilles Ohanessian ${ }^{\mathrm{a}, *}$ \\ a LCM, CNRS, Ecole Polytechnique, Université Paris-Saclay, 91128 Palaiseau, France \\ ${ }^{\mathrm{b}}$ Department of Chemistry, University of California, Berkeley, CA 94720, USA
}

\section{A R T I C L E I N F O}

\section{Article history:}

Received 22 July 2016

Received in revised form

28 December 2016

Accepted 10 January 2017

Available online 18 January 2017

In celebration of Jose Riveros' many essential contributions to gas phase ion chemistry.

\section{Keywords:}

Hydrated sulfate

IRPD spectroscopy

AMOEBA polarizable force field

Second hydration shell

Mixed quantum classical modelling

$\mathrm{O}-\mathrm{H}$ stretching frequency

\begin{abstract}
A B S T R A C T
Infrared photodissociation (IRPD) spectra of $\mathrm{SO}_{4}{ }^{2-}\left(\mathrm{H}_{2} \mathrm{O}\right)_{\mathrm{n}}, \mathrm{n}=9-13$, recorded in the cooled cell of a Fourier-transform ion cyclotron resonance mass spectrometer, between 2900 and $3800 \mathrm{~cm}^{-1}$, are reported. The structures, energetics and infrared spectra of $n=9$ and 11-13 were investigated by a combination of classical polarizable molecular dynamics and static quantum chemical calculations. Low-energy structures are mainly determined by the strong structuring effect of the sulfate ion, however, the highest cohesion is achieved when strong water-water interactions are present as well. As a result, the sulfate ion in the most stable structures for $\mathrm{n}=9,11$ and 12 is on the surface of the water cluster. While $\mathrm{SO}_{4}{ }^{2-}\left(\mathrm{H}_{2} \mathrm{O}\right)_{9}$ involves a mixture of isomers, the other sizes are found to be described by a single structural family, with the most stable structures of $\mathrm{SO}_{4}{ }^{2-}\left(\mathrm{H}_{2} \mathrm{O}\right)_{11}$ and $\mathrm{SO}_{4}{ }^{2-}\left(\mathrm{H}_{2} \mathrm{O}\right)_{13}$ deriving from that of $\mathrm{SO}_{4}{ }^{2-}\left(\mathrm{H}_{2} \mathrm{O}\right)_{12}$ by removal and addition of a water molecule, respectively, without substantial reorganization. An important feature of these structures is that the number of water molecules in the second solvation sphere increases with cluster size, up to 3 for $\mathrm{n}=12$ and 4 for $\mathrm{n}=13$. This is directly reflected in the IRPD spectra. All spectra display two main features in the $3150-3350$ and $3350-3650 \mathrm{~cm}^{-1}$ range, plus a small band near $3100 \mathrm{~cm}^{-1}$. The $3350-3650 \mathrm{~cm}^{-1}$ massif, which includes most bands arising from second sphere molecules, acquires larger intensity relative to that at $3150-3350 \mathrm{~cm}^{-1}$ which is mainly composed of stretches in first sphere molecules. Whereas most water molecules have ADD coordination (where A stands for acceptor and D stands for donor of a hydrogen bond), special cases, including DD and AADD account for bands at the red and blue ends of the spectra. Computed IR spectra are able to account for most experimental features, especially when anharmonicities are taken into account for the largest red shifts. Finally, the higher abundance of $\mathrm{n}=12$ relative to other sizes is related to a lower water evaporation rate constant, in good agreement with the water binding energy which is computed to be larger for $\mathrm{n}=12$ than for 13 .
\end{abstract}

(C) 2017 Elsevier B.V. All rights reserved.

\section{Introduction}

Hydrates of the sulfate dianion $\mathrm{SO}_{4}{ }^{2-}$ are found to be a key component in the environment, especially in atmospheric aerosol particles [1,2]. Sulfur dioxide is emitted in the atmosphere by both natural (biological decay and volcanic activity) and anthropogenic (mostly combustion of fossil fuels in power plants) processes. It is converted to sulfuric acid by reaction with water, oxygen, and other oxidants. Field measurements show that nucleation rates correlate

\footnotetext{
* Corresponding authors.

E-mail addresses: erw@berkeley.edu (E.R. Williams), gilles.ohanessian@polytechnique.edu (G. Ohanessian).
}

with the concentration of sulfuric acid, eventually leading to the formation of cloud condensation nuclei [3]. Aerosols of hydrated sulfate also play a key role in the homogeneous nucleation of ice particles in the upper troposphere [4]. Thus, a detailed understanding of sulfate hydration is of high importance.

A first step towards this understanding is the knowledge of the structure and dynamics of bare sulfate in water. To this end, sulfate-water clusters $\mathrm{SO}_{4}{ }^{2-}\left(\mathrm{H}_{2} \mathrm{O}\right)_{\mathrm{n}}$ in the gas phase are appropriate prototype systems. Thus, it is not surprising that these clusters have been the subject of intense research for more than a decade. While most early studies focused on small clusters in the $n=3-6$ range, experimental data have now grown to encompass $n$ ranging from 3 to 80 [5] and even ca.250 [6]. 
Small clusters in the $n=3-7$ range have been extensively characterized [7-21]. In particular, computational investigations by Head-Gordon and coworkers provide both a comprehensive picture of the low-energy structure manifold [16] and a thorough calibration of the performances of quantum chemical methods [17]. Many density functionals were compared to ab initio results at the current accuracy limit [18]. There have been several reports of quantum chemical computations for $n=12$, [10,11,20,21,27] with some debate over the issue of whether or not the first hydration shell of sulfate is closed at $n=12$. Finally, an extensive study for $n=3-50$ was published recently, using a sophisticated basinhopping Monte Carlo procedure for the exploration of potential energy surfaces [28].

A number of experimental techniques have been used to characterize the properties of $\mathrm{SO}_{4}{ }^{2-}\left(\mathrm{H}_{2} \mathrm{O}\right)_{\mathrm{n}}$ in a wide size range. Photoelectron spectra at room temperature of $n=3-40$ [19] displayed several bands corresponding to rather different binding energies and gradual changes with increasing size. This was interpreted in terms of the sulfate ion being deeply burried inside the water droplet for the larger clusters; however, there appeared to be no breaking point which would provide a clear indication of a structural transition in a specific size range.

Infrared (IR) spectra were recorded at low temperature in the $500-1800 \mathrm{~cm}^{-1}$ frequency range, for $\mathrm{n}=3-24$ [20]. Direct comparison with the spectrum in bulk water suggested easy band assignments to either sulfate or water bands. Splittings observed for specific sizes between the sulfate antisymmetric stretching bands were used to infer structural information. In addition, the appearance of a new band in the $n=13$ spectrum was taken as an indication that the first hydration shell may be complete at $n=12$, with the 13th molecule bound in a different manner, most probably in the second shell. Earlier BIRD experiments [21], whereby the rate of water evaporation can be determined for each cluster size, indicate a break at $n=12$, with a similar interpretation. Finally, high pressure mass spectrometric experiments [22,23] yielded sizeselective binding enthalpies and entropies. These results show a relatively uniform trend with size, with no specific property for $n=12$. However, the authors noted that the populations of structures undergoing dissociation may be different at their higher temperatures. The temperature dependence of isomer populations has also been pointed out for smaller clusters in the discussion of photoelectron spectra [15].

In a previous paper [24], a thorough computational exploration identified the several most stable structures of $\mathrm{SO}_{4}{ }^{2-}\left(\mathrm{H}_{2} \mathrm{O}\right)_{12}$ and $\mathrm{SO}_{4}{ }^{2-}\left(\mathrm{H}_{2} \mathrm{O}\right)_{13}$. The computed IR spectra were compared to experimental spectra in the $600-1800 \mathrm{~cm}^{-1}$ range to associate the latter to structures and assign experimental bands. In this size range, there is no shell-closing transition and even at $n=13$ the first hydration shell remains incomplete. However, IRPD spectra in the fingerprint region were not found to be fully structure-revealing.

In the present work, IRPD spectra of $\mathrm{SO}_{4}{ }^{2-}\left(\mathrm{H}_{2} \mathrm{O}\right)_{\mathrm{n}}(\mathrm{n}=9-13)$ are recorded in the $\mathrm{O}-\mathrm{H}$ stretch region $\left(2900-3800 \mathrm{~cm}^{-1}\right)$ and compared to computed spectra. The different types of vibrational modes that are probed, together with the larger size range investigated, provide significantly enhanced information about the structures and energetics of these cluster ions than was previously available. An extensive survey of the structural manifolds within this range of cluster sizes provides a comprehensive picture of cluster growth and a sound rationale to the observations.

\section{Experimental methods}

IRPD spectra of hydrated sulfate ions were acquired on a 7.0 T Fourier-transform ion cyclotron resonance (FT-ICR) mass spectrometer coupled to a tunable OPO/OPA tabletop laser system. A description of the experimental apparatus is reported elsewhere [25]. Briefly, hydrated ions are generated by electrospray ionization of $\sim 5 \mathrm{mM}$ aqueous solutions of $\mathrm{CuSO}_{4}$ (Fischer Scientific, Fair Lawn, NJ) dissolved in ultrapure water (Millipore, Billerica, MA). The solutions are loaded into borosilicate glass capillaries pulled to an inner tip diameter of $\sim 1 \mu \mathrm{m}$. A platinum wire in contact with the solution in the capillary is held at a potential of $\sim-700 \mathrm{~V}$ relative to the heated metal entrance capillary of the mass spectrometer to produce hydrated sulfate ions. Electrostatic lenses guide these ions into the FT-ICR cell through five stages of differential pumping. A pulse of dry nitrogen gas $\left(\sim 10^{-6}\right.$ Torr $)$ is introduced into the vacuum chamber through a piezoelectric valve for $\sim 5 \mathrm{~s}$ to aid the trapping and thermalization of the ions to a copper jacket [26] surrounding the cell. The copper jacket is maintained at a temperature of $133 \mathrm{~K}$ by a controlled flow of liquid nitrogen. Following ion accumulation there is a $\sim 5 \mathrm{~s}$ delay to allow the vacuum chamber to reach pressures of $<10^{-8}$ Torr. Ions of interest are subsequently mass-selected using a stored waveform inverse Fourier transform.

Mass-selected ions are photodissociated at specific frequencies using a tunable OPO/OPA laser system (LaserVision, Bellevue, WA) pumped by the $1064 \mathrm{~nm}$ fundamental of a Nd:YAG laser at a $10 \mathrm{~Hz}$ repetition rate (Continuum Surelight I-10, Santa Clara, CA). Irradiation times between 1 and $10 \mathrm{~s}$ provide substantial, but not complete, fragmentation of the precursor ion by the sequential loss of water molecules. A first-order photodissociation rate constant is then calculated from the relative abundances of precursor and fragment ions. The photodissociation rate constant is corrected for dissociation due to the absorption of ambient blackbody photons from the ion cell and jacket as well as frequency-dependent variations in laser power.

\section{Computational methods}

The potential energy surfaces for $n=9$ and 11 were explored using a combination of classical molecular dynamics (MD) and quantum chemical calculations, implementing the procedure described previously for $n=12$ and 13 [24]. MD simulations were carried out using the polarizable AMOEBA force field (using the AMOEBA03 parameters for water as available in the Tinker software [31], and the sulfate parameters from reference 16). They were propagated from several starting points (four for $n=9$ and eight for $n=11$ ) chosen to ensure both structural and energetic diversity, in order to make the structural search as comprehensive as possible. From each of these structures, MD trajectories were propagated at $200 \mathrm{~K}$ with parameters given and discussed previously [24]. Snapshots at $200 \mathrm{ps}$ intervals were then used as starting points for local geometry optimization using density functional theory (DFT), using the M11 density functional and the $6-311++G(d, p)$ atomic basis set. M11 has been shown to be accurate on relative energies for $n=3-7$ by Head-Gordon and coworkers [18]. A total of 72 and 165 DFT calculations were run in this manner for $n=9$ and 11 , respectively, followed by vibrational spectrum calculations in the harmonic approximation. Anharmonic spectra were also computed for some of the most stable structures of each size. Lastly, energies were refined at the ab initio level.

As described in previous studies [24,28], water clusters contain numerous cyclic patterns held together by hydrogen bonds. Reversal of the latter along one or several cycle(s) generates structures which, although sharing a common skeleton, establish different interactions with the rest of the cluster. Energy differences are usually on the order of a few $\mathrm{kJ} \mathrm{mol}^{-1}$. Such structures are only partly sampled by the exploration procedure described above. Thus, we have used the 'cycle tracker' tool $[28,29]$ to generate such isomers systematically from the lowest-energy isomers found. In what 
Table 1

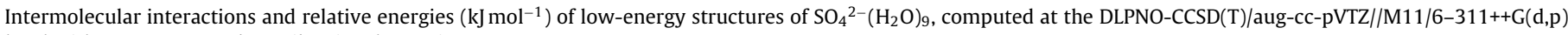
level with M11-computed $0 \mathrm{~K}$ vibrational energies.

\begin{tabular}{|c|c|c|c|c|c|c|}
\hline Structure name & Sulfate coordination & First vs second hydration sphere & $\mathrm{H}$ bonding pattern & Relative E $0 \mathrm{~K}$ & Relative E $130 \mathrm{~K}$ & Relative G $130 \mathrm{~K}$ \\
\hline W9-1 & {$[3,2,2,2]$} & All in first & All ADD & 0.0 & 0.0 & 0.0 \\
\hline W9-2 & {$[3,2,2,2]$} & One in second & $\begin{array}{l}\text { One AADD } \\
\text { one DD }\end{array}$ & 2.1 & 2.6 & -0.8 \\
\hline W9-3 & {$[3,2,2,2]$} & One in second & All ADD & 4.6 & 5.0 & 2.1 \\
\hline W9-4 & {$[3,2,2,2]$} & One in second & All ADD & 4.6 & 4.9 & 3.4 \\
\hline W9-5 & {$[3,2,2,2]$} & One in second & One DD & 6.0 & 7.3 & 1.6 \\
\hline W9-6 & {$[3,3,2,2]$} & One in second & One DD & 6.2 & 7.5 & 1.4 \\
\hline W9-7 & {$[3,2,2,2]$} & All in first & All ADD & 8.4 & 9.8 & 2.5 \\
\hline
\end{tabular}

Table 2

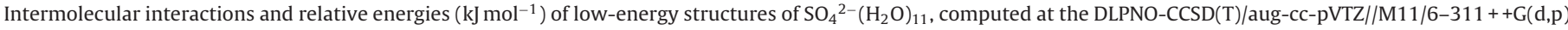
level with M11-computed $0 \mathrm{~K}$ vibrational energies.

\begin{tabular}{|c|c|c|c|c|c|c|}
\hline Structure name & Sulfate coordination & First vs second hydration sphere & $\mathrm{H}$ bonding pattern & Relative E $0 \mathrm{~K}$ & Relative E $130 \mathrm{~K}$ & Relative G $130 \mathrm{~K}$ \\
\hline W11-1 & {$\left[4^{\prime}, 2,2,2\right]$} & Two in second & One AADD one AD & 0.0 & 0.0 & 0.0 \\
\hline W11-2 & {$\left[3,3^{\prime}, 2,2\right]$} & Two in second & One AADD & 3.8 & 4.2 & 3.2 \\
\hline W11-3 & {$\left[3,3^{\prime}, 2,2\right]$} & Two in second & One AADD one AD & 4.0 & 4.3 & 4.1 \\
\hline W11-4 & {$\left[4^{\prime}, 2,2,2\right]$} & Two in second & One AADD one AD & 5.2 & 5.5 & 4.2 \\
\hline W11-5 & {$[3,2,2,2]$} & Three in second & Two AADD & 5.4 & 5.1 & 6.6 \\
\hline W11-6 & {$\left[4^{\prime}, 2,2,2\right]$} & Two in second & Two AADD one AD & 7.7 & 8.9 & 5.3 \\
\hline W11-7 & {$\left[4^{\prime}, 2,2,2\right]$} & Two in second & One AADD one AD & 7.7 & 8.0 & 7.8 \\
\hline W11-8 & {$[3,2,2,1]$} & Two in second & Two AADD & 9.1 & 8.3 & 11.7 \\
\hline W11-9 & {$[3,2,2,2]$} & Two in second & One AADD one AD & 13.6 & 14.9 & 10.9 \\
\hline
\end{tabular}

follows, only the lowest-energy member of each such family is described, unless otherwise stated.

As described previously for clusters with $n=3-7$ [16], the energy ordering is modified by inclusion of zero-point vibrational energy (ZPE). Thus, all results below include ZPE computed at the M11 level. Vibrational spectra were computed at the M11/6-311++G(d,p) level. All frequencies were scaled by 0.945 , a factor determined so as to match the experimental [5] stretching frequency of free $\mathrm{O}-\mathrm{H}$ bonds at $3710 \mathrm{~cm}^{-1}$ which appears to be independent of cluster size. This was done on larger clusters than those described herein (work in progress).

As in previous work [24], it was deemed important to obtain final energetics at more accurate levels than M11/6-311++G(d,p). To this end, energetics at the M11 geometries were obtained at the [DLPNO-CCSD(T)] [30] level, combined with the aug-cc-pVTZ basis set. These are reported in Tables 1 and 2 and in the text below. Structures, relative energies and spectra computed at other levels are available as Supplementary Information (see Table S1).

MD calculations were run using the Tinker 6 package [31]. DFT calculations were conducted using the Gaussian09 package [32], while DLPNO-CCSD(T) wavefunctions were computed with the Orca 3.0.3 package [33].

\section{Results}

\subsection{Experimental spectra for $n=9-13$}

Experimental IRPD spectra are shown in Fig. 1. The series displays several significant trends. The main absorption regions appear as two massifs, in the $3150-3350$ and $3350-3650 \mathrm{~cm}^{-1}$ ranges. While the two are clearly distinguishable for $n=9$ and 10 , the lower frequency part appears as a large shoulder in the spectra of $n=11-13$. There also appears a small band near $3100 \mathrm{~cm}^{-1}$ for all sizes, although it is more distinct for $n=9$ and 10 . There is, at the other end of the spectrum, no sign of light absorption beyond ca. $3650 \mathrm{~cm}^{-1}$, indicating the absence of purely dangling $\mathrm{O}-\mathrm{H}$ bonds at the clusters' surfaces, which would be expected to appear near $3710 \mathrm{~cm}^{-1}$ [5].

These spectra indicate that most $\mathrm{O}-\mathrm{H}$ stretching bands are strongly red shifted relative to those of an isolated water molecule.

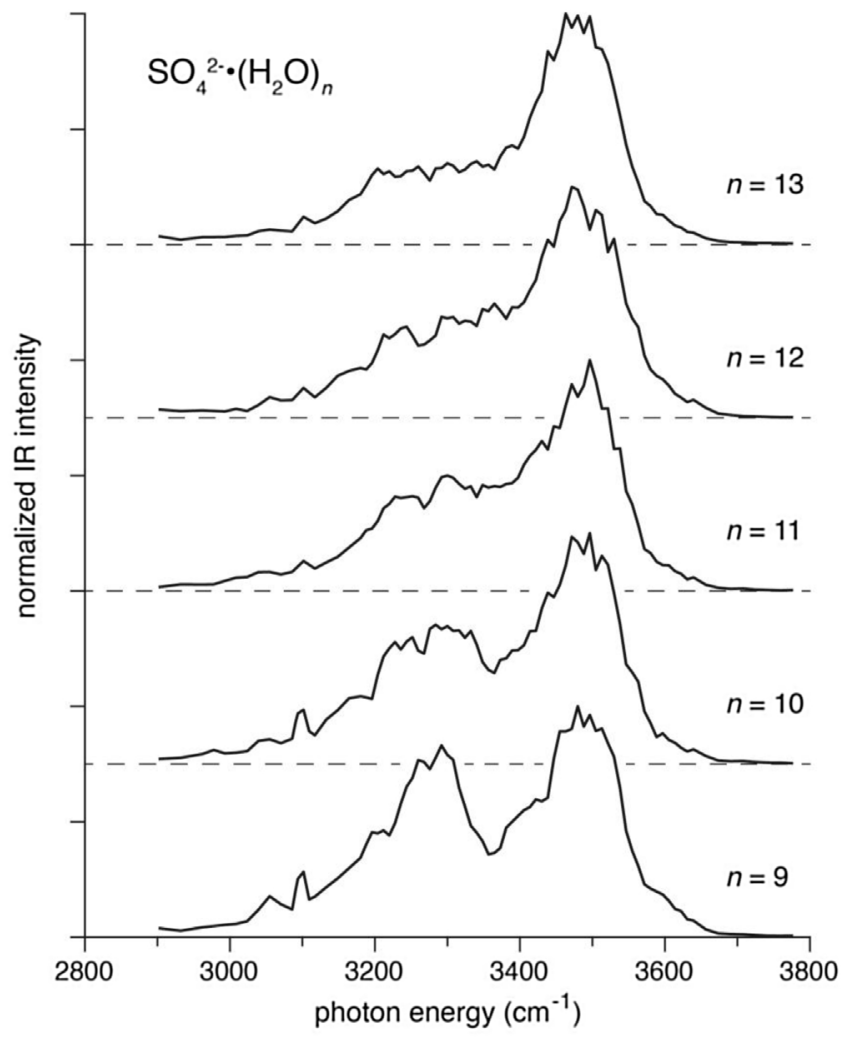

Fig. 1. Experimental IRPD spectra of $\mathrm{SO}_{4}{ }^{2-}\left(\mathrm{H}_{2} \mathrm{O}\right)_{n}, \mathrm{n}=9-13$, recorded at $130 \mathrm{~K}$.

This may be attributed partly to the strength of the ionic hydrogen bonds to the sulfate oxygen atoms, each of the latter bearing a net charge of ca. -1 [34]. As discussed in more detail below, the $3150-3350 \mathrm{~cm}^{-1}$ massif can thus be assigned mostly to the elongations of $\mathrm{O}-\mathrm{H}$ bonds pointing toward a sulfate $\mathrm{O}$, complemented with vibrations of the few AADD molecules, whose O-H stretching frequencies are more red shifted than those of the ADD. Here, each " $A$ " indicates that the water oxygen accepts a hydrogen bond and each " $D$ " means that one of the hydrogens is a donor. The 

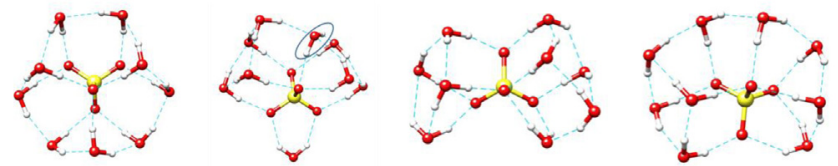

W9-1

W9-2

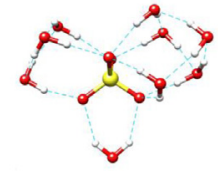

W9-5

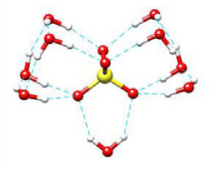

W9-6
W9-3

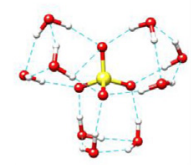

W9-7
Fig. 2. Structures of low-energy isomers of $\mathrm{SO}_{4}{ }^{2-}\left(\mathrm{H}_{2} \mathrm{O}\right)_{9}$. The ordering in W9-" $\mathrm{x}$ " is based on DLPNO-CCSD(T)/aug-cc-pVTZ//M11/6-311++G(d,p) relative energies, including M11 zero-point vibrational energies. The molecule circled in W9-2 is the single case of AADD coordination.
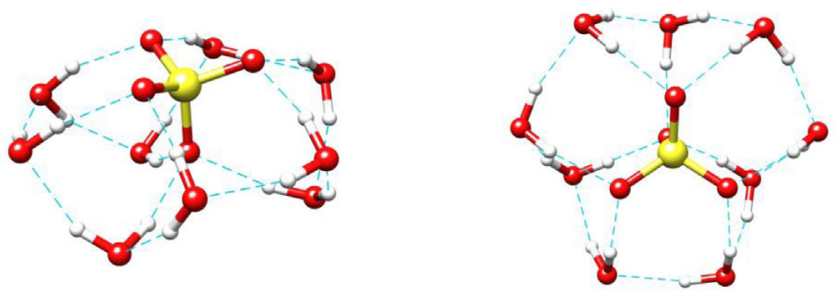

Scheme 1. Two views of the lowest-energy structure W9-1 of $\mathrm{SO}_{4}{ }^{2-}\left(\mathrm{H}_{2} \mathrm{O}\right)_{9}$.

$3350-3650 \mathrm{~cm}^{-1}$ feature arises largely from $\mathrm{O}-\mathrm{H}$ bonds engaged in water-water interactions, although some combinations of $\mathrm{O}-\mathrm{H}$ stretches toward the sulfate also have relatively high frequencies. Water molecules residing in the second hydration shell of the ion induce significant spectral differences in comparison to small clusters in which all molecules are expected to interact directly with the sulfate ion, as has been amply characterized for $n=3-6$ [12-21]. Thus, the change in the relative intensities of the two broad spectral features, with the blue part growing relative to the red part when the cluster size increases, is consistent with the rise of the second hydration shell.

\subsection{Structures and energetics for $\mathrm{SO}_{4}{ }^{2-}\left(\mathrm{H}_{2} \mathrm{O}\right)_{9}$}

The low-energy structures of $\mathrm{SO}_{4}{ }^{2-}\left(\mathrm{H}_{2} \mathrm{O}\right)_{9}$ are shown in Fig. 2; some structural indicators as well as associated energies are given in Table 1.

The lowest-energy structure, W9-1 (see Scheme 1 ), has $C_{3}$ symmetry with three water trimers, each making a four-membered ring with a sulfate oxygen bound to both ends, and the central water bound to another sulfate oxygen. Each water trimer is also bound to the other two. This makes a compact structure, with 3 sulfate oxygens being di-coordinated and one being tri-coordinated (termed $[3,2,2,2]$ sulfate coordination pattern) and the ion at the cluster surface, much like the most stable structure of $\mathrm{SO}_{4}{ }^{2-}\left(\mathrm{H}_{2} \mathrm{O}\right)_{12}$ [24]. Two views of W9-1 are shown in Scheme 1; the left view highlights the position of the sulfate ion near the water cluster surface. The right view is a top view slightly off an $\mathrm{S}-\mathrm{O}$ axis with the interior $\mathrm{O}$ in the back. As can be seen, all water molecules have an ADD bonding pattern.

The next most stable structure, W9-2, is quite different although it also has $[3,2,2,2]$ sulfate coordination. It consists of two fourmembered water rings: one donating four bonds to the sulfate, while the other donates three bonds to the sulfate and one to the other water ring. This connection between the two rings generates an AADD molecule, a bonding pattern which is absent in W9-1. It also has one molecule in the second coordination sphere of the sulfate, another feature which was not found in any other structure. The structure is completed by a single water molecule chelating between two sulfate O's, thus of DD type. The third structure, W9-3, is similar to W9-2, again containing two four-membered water rings. In this case, one is donating four bonds to the sulfate, while the other donates three bonds to the sulfate and one to the water molecule, which chelates between two sulfate O's. Thus, the two water tetramers are not connected in this case, and all water molecules are ADD. W9-6 also has two four-membered water rings, however, both donate four bonds to the sulfate and are thus connected neither to the chelating molecule, which is DD-bonded, nor to one another. W9-5 has one three-membered water ring connected three times to the sulfate, and one five-membered water ring connected four times to the sulfate. The chelating molecule is again DD.

W9-4 is different from all others, with a four-membered water ring having three $\mathrm{O}-\mathrm{H}$ bonds towards the sulfate, connected to a linear chain of five water molecules which terminates with a water chelating between two sulfate O's. All water molecules are ADD in this case. Finally W9-7 bears three non-interacting water trimers, each making three bonds to the sulfate, i.e. all molecules are ADD in the first sphere. This structure has been invoked previously as the most stable of $\mathrm{SO}_{4}{ }^{2-}\left(\mathrm{H}_{2} \mathrm{O}\right)_{9}[20,28]$.

Relative energies computed at the DLPNO-CCSD(T)/aug-ccpVTZ//M11/6-311++G(d,p) level are given in Table 1. W9-1 is the most stable structure in terms of energy, with a Boltzmann population of ca. $90 \%$ at $130 \mathrm{~K}$. When entropy effects are taken into account, the situation changes and the highest population is that of W9-2 (see Table S2). Clearly this is due to the larger strain in W9-1. At $130 \mathrm{~K}$, minor populations are also predicted for W9-3, W9-5 and W9-6 based on their free energies.

\subsection{IR spectra for $\mathrm{SO}_{4}{ }^{2-}\left(\mathrm{H}_{2} \mathrm{O}\right)_{9}$}

Computed IR spectra of $\mathrm{SO}_{4}{ }^{2-}\left(\mathrm{H}_{2} \mathrm{O}\right)_{9}$ isomers are displayed in Fig. 3 along with the experimental IRPD spectrum. Differences between computed spectra are immediately obvious. The spectrum for W9-1 is bimodal, however with a much narrower distribution of frequencies than in the experimental spectrum. In this structure, all water molecules have ADD bonding patterns. The lowest-frequency modes are $\mathrm{O}-\mathrm{H}$ stretches towards the sulfate, up to $>3400 \mathrm{~cm}^{-1}$. The most intense bands near $3440 \mathrm{~cm}^{-1}$ correspond to mixtures of $\mathrm{O}-\mathrm{H} \cdots$ sulfate (major) and $\mathrm{O}-\mathrm{H} \cdots$ water stretches (minor), and higher frequencies also involve mixtures with progressively dominant $\mathrm{O}-\mathrm{H} \cdots$ water contributions. The latter are quasi exclusive at the highest frequencies between 3470 and $3480 \mathrm{~cm}^{-1}$. Clearly this structure alone cannot account for the experimental spectrum.

The spectrum of W9-2 extends over a much wider frequency window. While band assignments are very similar to those of W91 in the $3350-3500 \mathrm{~cm}^{-1}$ range, other bands arise mostly from the presence of AADD and DD water molecules. The DD molecule makes two strongly frustrated interactions with sulfate O's. This leads to two bands at 3536 and $3558 \mathrm{~cm}^{-1}$. In addition, the AADD molecule is an acceptor of a highly frustrated hydrogen bond (distance of $2.07 \AA$, angle of $143^{\circ}$ ), leading to a band at $3559 \mathrm{~cm}^{-1}$. On the red side, two bands arise mostly from the $\mathrm{O}-\mathrm{H}$ stretches of the AADD molecule, at 3304 and $3327 \mathrm{~cm}^{-1}$. Several bands at 3319, 3344 and $3357 \mathrm{~cm}^{-1}$ arise from first sphere $\mathrm{O}-\mathrm{H}$ stretches towards the sulfate, at lower frequencies than in W9-1 because the four membered rings allow for better oriented and thus stronger hydrogen bonds to the sulfate.

The spectrum of W9-3 differs slightly from that of W9-2. At the blue end, the water chelating between two sulfate O's is now ADD instead of DD, leading to significant red shifts of both bands. At the 


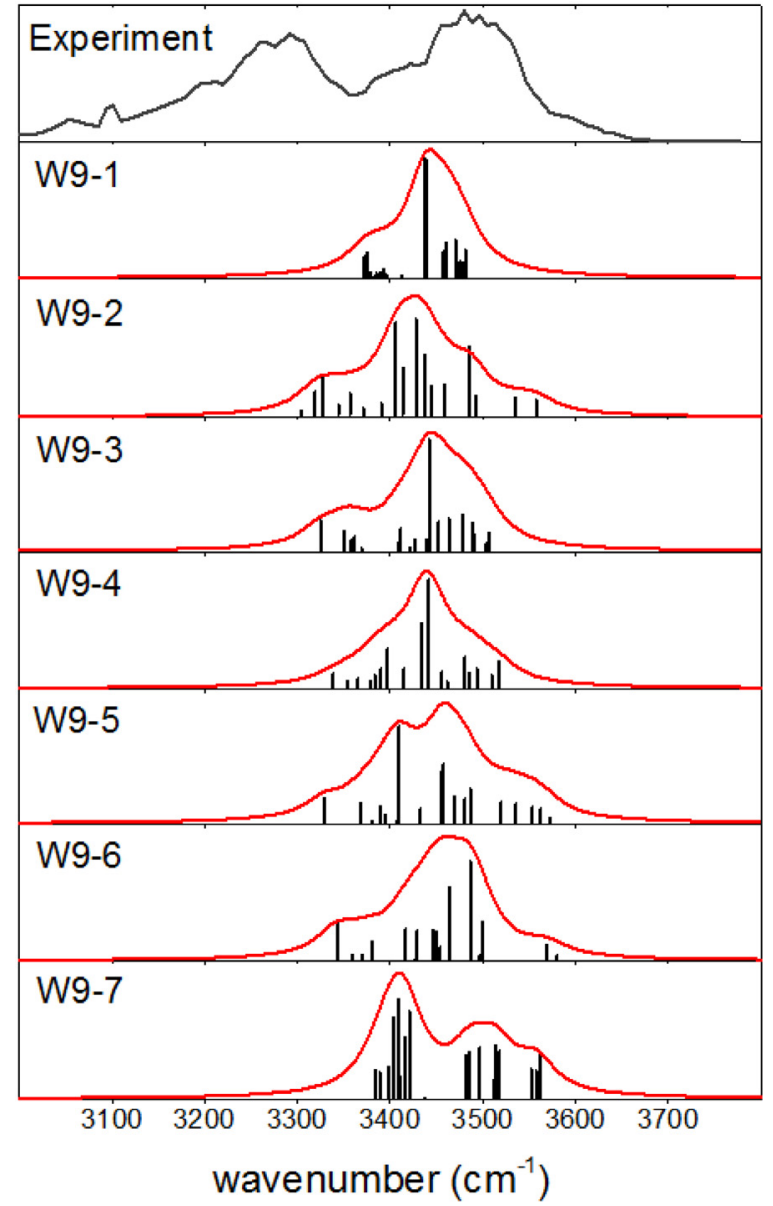

Fig. 3. Experimental IRPD spectrum (top) and computed absorption spectra (M11/6-311 ++G(d,p) level) of several low-energy isomers of $\mathrm{SO}_{4}{ }^{2-}\left(\mathrm{H}_{2} \mathrm{O}\right)_{9}$. Structures and spectra are at the $M 11 / 6-311++G(d, p)$ level.

red end, the absence of an AADD molecule leads to blue shifting of the two bands, still leaving a spectrum which is more spread out than that of W9-1, due to the four-membered water cycles.

The same reasoning can be used to understand the main features of the other spectra displayed in Fig. 3. For instance, the high symmetry of W9-7 leads to groups of bands, and the constrained 3membered water rings lead to non-optimum hydrogen bonds and thus global blue-shifting of many bands relative to those of other structures.

Temperature and entropy effects lead to a mixture with leading populations of W9-1 and W9-2 (see Table S2). The latter accounts well for the higher frequency portion of the spectrum, while its extension to the red can only partly account for the experimental massif, and lacks the band near $3100 \mathrm{~cm}^{-1}$. This failure to describe large red shifts is expected when the harmonic approximation is used; anharmonic calculations described in a later section do display significant absorption at $3100 \mathrm{~cm}^{-1}$ for W9-2 (see Fig. S1).

\subsection{Structures and IR spectra for $\mathrm{SO}_{4}{ }^{2-}\left(\mathrm{H}_{2} \mathrm{O}\right)_{12}$}

The structures and relative energies of the most stable forms of $\mathrm{SO}_{4}{ }^{2-}\left(\mathrm{H}_{2} \mathrm{O}\right)_{12}$ have been described in detail previously [24]. The most stable are recalled here, before those of $\mathrm{SO}_{4}{ }^{2-}\left(\mathrm{H}_{2} \mathrm{O}\right)_{11}$, since the most stable structures of $\mathrm{SO}_{4}{ }^{2-}\left(\mathrm{H}_{2} \mathrm{O}\right)_{11}$ and $\mathrm{SO}_{4}{ }^{2-}\left(\mathrm{H}_{2} \mathrm{O}\right)_{13}$ are adequately described from that of $\mathrm{SO}_{4}{ }^{2-}\left(\mathrm{H}_{2} \mathrm{O}\right)_{12}$ by removing and adding one water molecule, respectively.

A single structural family was found to account for most of the ion population at $130 \mathrm{~K}$, where "family" is meant to include

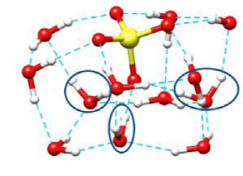

W12-1

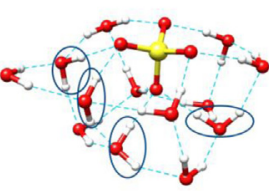

W13-1a

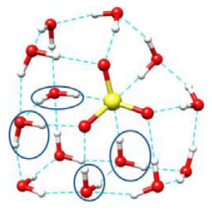

W13-2
Scheme 2. Lowest-energy structure W12-1 of $\mathrm{SO}_{4}{ }^{2-}\left(\mathrm{H}_{2} \mathrm{O}\right)_{12}$ and the two most stable structures W13-1a and W13-2 of $\mathrm{SO}_{4}{ }^{2-}\left(\mathrm{H}_{2} \mathrm{O}\right)_{13}$. AADD molecules are circled.

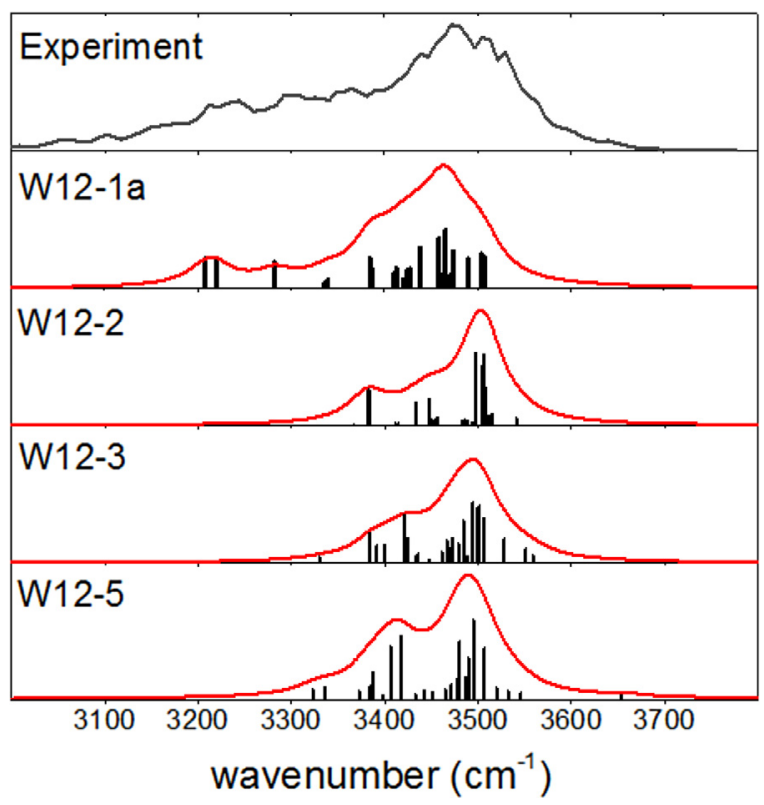

Fig. 4. Experimental IRPD spectrum (top) and computed absorption spectra of several low energy isomers of $\mathrm{SO}_{4}{ }^{2-}\left(\mathrm{H}_{2} \mathrm{O}\right)_{12}$. Structures and spectra are at the M11/6-311++G(d,p) level.

a set of structures which are related to one another by inversion of hydrogen bond orientations along one or several cycles of water molecules. The most stable is depicted on the left part of Scheme 2. It has 3-fold symmetry, [3,2,2,2] sulfate coordination, with nine water molecules in ADD and three in AADD networks (the latter are circled in this and other structures in Scheme 2). An important feature regarding the IR spectrum is that three out of the nine ADD water molecules reside in the second sulfate hydration shell.

In this high symmetry structure, there are three different types of water molecules: six are ADD in the first sphere (those at the top in Scheme 2), three are ADD in the second sphere and three are AADD in the first sphere (the last two types are alternating at the bottom in Scheme 2). The rest of the structures may be found in reference 24.

In the spectrum computed for W12-1 (see Fig. 4) the bands between 3200 and $3300 \mathrm{~cm}^{-1}$ arise from $\mathrm{O}-\mathrm{H}$ stretchings toward the sulfate in AADD molecules. Above $3300 \mathrm{~cm}^{-1}$, both AADD and ADD bonds to the sulfate are dominant, and $\mathrm{O}-\mathrm{H}$ bonds that interact with other water molecules start being active. At increasing frequencies, modes become strongly delocalized and second shell molecules are also active. At $3490 \mathrm{~cm}^{-1}$, six in-phase ADD stretches towards the sulfate generate a rather unfavorable motion, and finally, the antisymmetric stretching bands of the second sphere molecules appear just above $3500 \mathrm{~cm}^{-1}$. The global pattern seen for $n=9$ applies again: most $\mathrm{O}-\mathrm{H} \cdots$ sulfate bands on the red side, most $\mathrm{O}-\mathrm{H} \cdots \mathrm{O}$ bands on the blue side, yet with strong overlap between the two groups and some exceptions. In addition, AADD water molecules extend the frequency range at the red end and sec- 


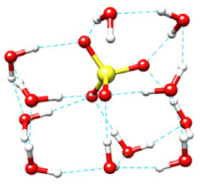

W11-1

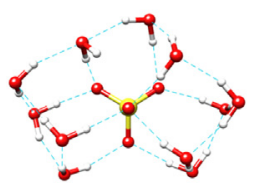

W11-4

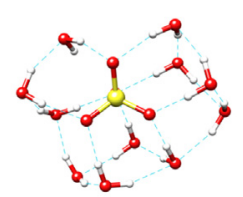

W11-7

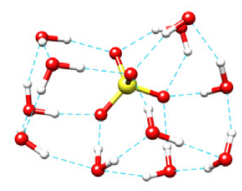

W11-2

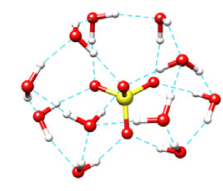

W11-5

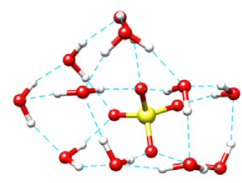

W11-8

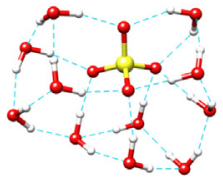

W11-3

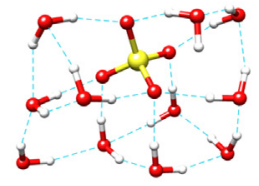

W11-6

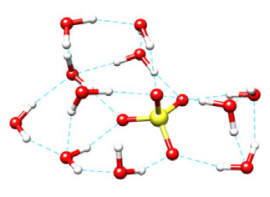

W11-9
Fig. 5. Structures of low-energy isomers of $\mathrm{SO}_{4}{ }^{2-}\left(\mathrm{H}_{2} \mathrm{O}\right)_{11}$. The ordering in W11- " $\mathrm{x}$ " is based on DLPNO-CCSD $(\mathrm{T}) /$ aug-cc-pVTZ//M11/6-311 $++\mathrm{G}(\mathrm{d}, \mathrm{p})$ relative energies, including M11 zero-point vibrational energies.

ond sphere water molecules generate new bands at the blue end. These principles can be used to assign the spectra of other isomers of $n=12$. Their populations at $130 \mathrm{~K}$ are computed to be very small and their spectra are inconsistent with the experimental spectrum (Fig. 4).

The question arises of the potential fluxionality offered by inversions of hydrogen bond orientations along one or several cycles of water molecules, and its potential impact on the IR spectrum. To this end, a transition state was determined for inversion along one of the four-membered rings, i.e., concerted transfer of four hydrogens. It was found to lie $111 \mathrm{~kJ} \mathrm{~mol}^{-1}$ higher in energy than W12-1 at the M11/6-311++G(d,p) level. Such a high energy barrier is due to the contraction of the four-membered ring when the four $\mathrm{O}-\mathrm{H}$ bonds are stretched and four new bonds are being formed. This puts strong, destabilizing constraints on the hydrogen bonds to the sulfate oxygens. This barrier is nearly twice as large as that for water evaporation, see Section 5.5, making such a mechanism quite unlikely. Yet stepwise rearrangements, involving a series of hydrogen bond breakages and bond re-formations elsewhere, should be considered to fully assess the possibility of isomer interconversion without evaporation.

\subsection{Structures, energetics and IR spectra for $\mathrm{SO}_{4}{ }^{2-}\left(\mathrm{H}_{2} \mathrm{O}\right)_{11}$}

A total of 165 structure optimizations were carried out at the DFT level for $\mathrm{SO}_{4}{ }^{2-}\left(\mathrm{H}_{2} \mathrm{O}\right)_{11}$. The low-energy structures are shown in Fig. 5, the spectra are given in Fig. 6 and their energies are in Table 2.

The lowest-energy structure, W11-1, was formed in all simulation runs used to explore the potential energy surface, much more frequently than any other structure. It derives from the most stable structure W12-1 of $\mathrm{SO}_{4}^{2-}\left(\mathrm{H}_{2} \mathrm{O}\right)_{12}$ since it is made of two cyclic water tetramers, each making three interactions to three sulfate oxygens and one to another water molecule. This leads to ['4',2,2,2] sulfate coordination and two water molecules in the second hydration sphere. The missing water molecule generates a weakly bound $\mathrm{O}-\mathrm{H}$ bond in the remaining water trimer, however the corresponding band at $3658 \mathrm{~cm}^{-1}$ is of very low intensity. The rest of the spectrum is very similar to that of W12-1. The next

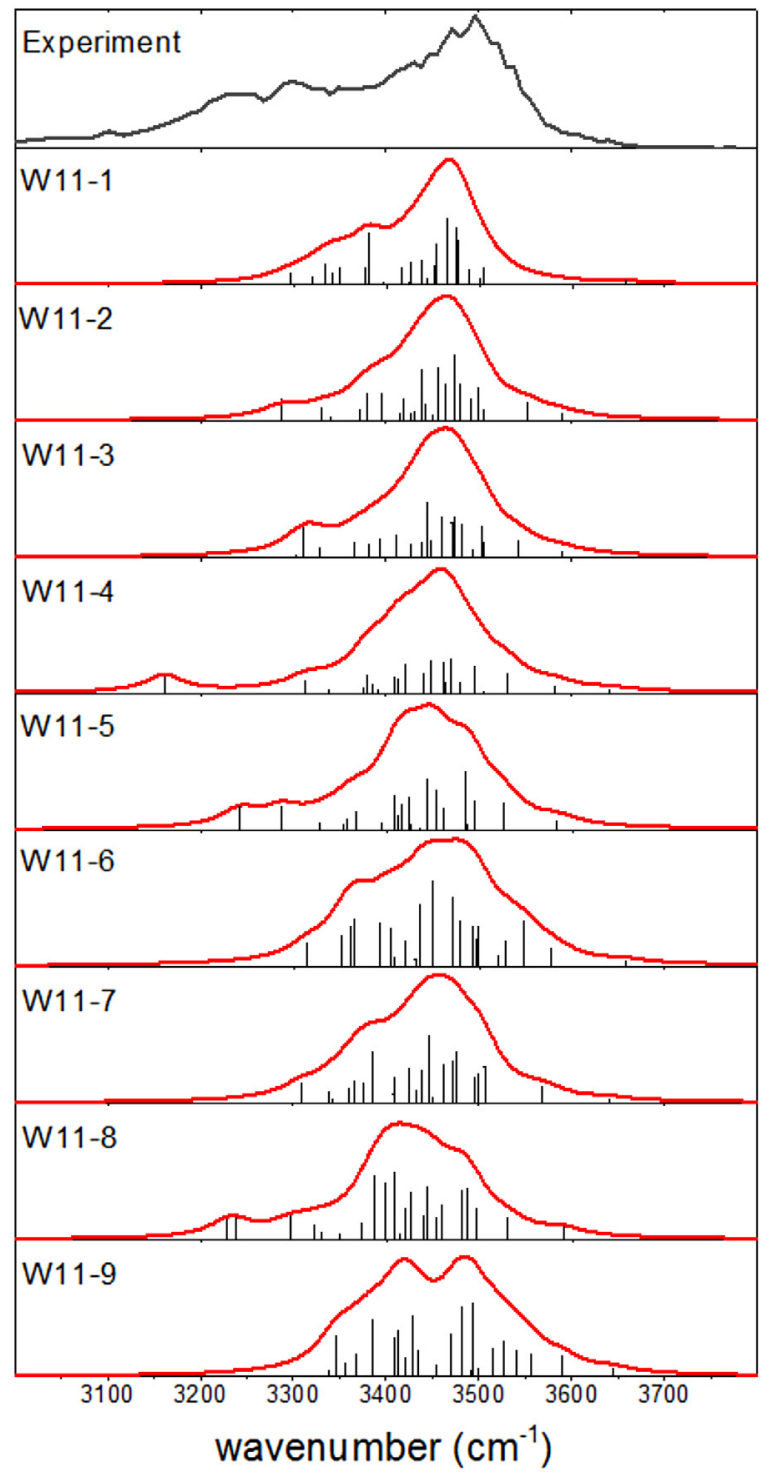

Fig. 6. Experimental IRPD spectrum (top) and computed absorption spectra of several low-energy isomers of $\mathrm{SO}_{4}{ }^{2-}\left(\mathrm{H}_{2} \mathrm{O}\right)_{11}$. Structures and spectra are at the M11/6-311++G(d,p) level.

most stable structure, W11-2, also bears a water tetramer, however, the rest of the cluster is more distorted relative to W12-1, with a second tetramer sharing a water molecule with the first. The shared water molecule has AADD coordination, with a red-shifted $\mathrm{O}-\mathrm{H} \cdots$ sulfate stretch at $3287 \mathrm{~cm}^{-1}$. The two hydrogen bonds it receives are far from making a tetrahedral arrangement, leading to a band with limited shift at $3552 \mathrm{~cm}^{-1}$. Another water molecule bridges between two sulfate oxygens, with ADD coordination and stretching bands at 3589 and $3430 \mathrm{~cm}^{-1}$, both with very low intensity. The third structure, W11-3, is rather similar to W11-2 with two water tetramers sharing an AADD water molecule. Its $\mathrm{O}-\mathrm{H}$. . sulfate stretching at $3312 \mathrm{~cm}^{-1}$ is somewhat less red-shifted than in the previous case, in agreement with the larger $\mathrm{H}$ bond distance (1.768 vs $1.742 \AA$ ). The rest of the cluster is rather similar and the bridging water has stretching frequencies of 3589 and $3427 \mathrm{~cm}^{-1}$.

The same principles can be used to rationalize the features of the other calculated spectra. For instance W11-8 has two AADD water molecules with short hydrogen bonds to sulfate O's of 1.734 and $1.741 \AA$, with corresponding low frequencies of 3227 and $3238 \mathrm{~cm}^{-1}$, respectively. At the other end of the spectrum, the high 


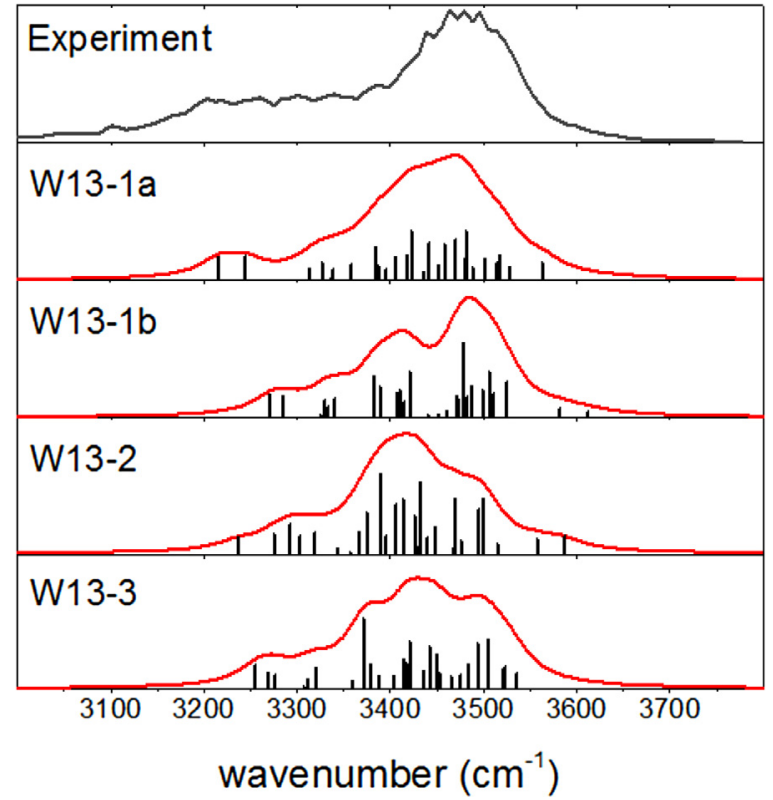

Fig. 7. Experimental IRPD spectrum (top) and computed absorption spectra of several low-energy isomers of $\mathrm{SO}_{4}{ }^{2-}\left(\mathrm{H}_{2} \mathrm{O}\right)_{13}$. Structures and spectra are at the M11/6-311++G(d,p) level.

frequency band at $3589 \mathrm{~cm}^{-1}$ arises from a hydrogen bond to an AADD molecule, which is again far from optimum. W11-4 includes the strongest red shift of all spectra in Fig. 6; it corresponds to an AADD molecule with a particularly short bond to the sulfate of $1.708 \AA$, as its other $\mathrm{O}-\mathrm{H}$ is only weakly hydrogen bonded.

It appears that most of the low-energy structures of $\mathrm{SO}_{4}{ }^{2-}\left(\mathrm{H}_{2} \mathrm{O}\right)_{11}$ can be described as deriving from W12-1. The general principles of band assignment seen for $\mathrm{SO}_{4}{ }^{2-}\left(\mathrm{H}_{2} \mathrm{O}\right)_{12}$ are operative here as well. Yet, the missing water molecule generates significant distortions leading to one or two of the following features: (i) one weakly bound $\mathrm{O}-\mathrm{H}$, with a small band at higher frequency than those in the W12-1 spectrum, and (ii) one AADD molecule in the first hydration sphere, for which interaction with the sulfate generates a band at the lower frequency end.

The computed populations at $130 \mathrm{~K}$ (see Table S3) indicate that W11-1 accounts for ca. $90 \%$ of the ions observed in this temperature range. Yet the small contributions of W11-2, W11-3 and W11-4 explain the blue end of the experimental absorption, with bands near 3550 and $3590 \mathrm{~cm}^{-1}$. As seen previously for $n=9$, the harmonic approximation does not allow for a satisfactory description of the largest red shifts due to the strongest hydrogen bonds, leading to a truncated red end below $3250 \mathrm{~cm}^{-1}$.

\subsection{Structure and IR spectra for $\mathrm{SO}_{4}{ }^{2-}\left(\mathrm{H}_{2} \mathrm{O}\right)_{13}$}

The structures and relative energies of the most stable forms of $\mathrm{SO}_{4}{ }^{2-}\left(\mathrm{H}_{2} \mathrm{O}\right)_{13}$ have been described in detail previously [24]. Among the most stable, W13-1a and W13-2 are shown in Scheme 2, whereas some of the spectra are displayed in Fig. 7. The lowenergy structures W13-1 $\mathrm{x}$ are all based on W12-1, adding a water molecule to several possible sites (this is described in detail in reference 24). The computed spectra for W13-1a and W13-1b, shown in Fig. 7, are in good overall agreement with the experimental one. Bands in the $3200-3300 \mathrm{~cm}^{-1}$ range arise from the first shell AADD molecules, as described above for W12-1. Differences between W13-1a and W13-1b are due to the " $13^{\text {th" }}$ water molecule, bridging between two water molecules in the first case and between two sulfate oxygens in the second. In the first case, this binding generates two additional AADD molecules, red-shifting their stretching bands to the $3300-3350 \mathrm{~cm}^{-1}$ range. At the blue end lie the two $\mathrm{O}-\mathrm{H}$ stretching frequencies of the bridging molecule since this chelation is too strained to form two strong hydrogen bonds. The frequencies are different (3528 and $3563 \mathrm{~cm}^{-1}$ for W13-1a; 3583 and $3613 \mathrm{~cm}^{-1}$ for W13-1b) since their binding partners are different. Although the experimental spectra are very similar for $\mathrm{n}=12$ and 13 , calculations predict some distinctive features in the higher frequency range for $n=13$ as compared to $n=12$.

W13-2 is much different than w13-1 (see Scheme 2) as it is mostly made of a cubic water motif in which two water molecules are replaced by a sulfate $\mathrm{S}-\mathrm{O}$ bond, which is itself fused with two incomplete cubes. As in W13-1a, there are 4 molecules in the second hydration shell. The cube includes four AADD molecules in the first sphere, leading to low frequency stretching motions similar to those in W13-1 (see Fig. 7). The highest frequencies at 3558 and $3587 \mathrm{~cm}^{-1}$ arise from $\mathrm{O}-\mathrm{H}$ bonds pointing toward AADD molecules since in this case again, the cluster is too small to accommodate AADD coordination in a nearly tetrahedral fashion. W13-2 is of very low energy and its spectrum is similar enough to that of W13-1 that it is likely to contribute to the experimentally observed absorptions. W13-3 is of slightly higher energy and its spectrum is in less good agreement with experiment, with a most intense band below $3400 \mathrm{~cm}^{-1}$, therefore its population is likely to be small. In conclusion, a combination of several structures of the W13-1 family (including W13-1a and W13-1b shown in Fig. 7) together with a smaller contribution of W13-2 account very well for the experimental spectrum.

\section{Discussion}

\subsection{Comparison of experimental and computational spectra}

The agreement between the experimental and computed spectra is generally good but depends on the cluster size. For $n=12$, the lowest energy family of structures accounts well for the entire spectrum, except for a possible small band near $3100 \mathrm{~cm}^{-1}$. For $\mathrm{n}=13$, a mixture of structures, all deriving from W12-1 by adding a water molecule to several possible sites, is also able to describe all experimentally observed features. For $n=11, \mathrm{~W} 11-1$ together with minor amounts of W11-2, W11-3 and W11-4 (see populations computed at $130 \mathrm{~K}$ in Table S3) accounts for most of the experimental spectrum, however, the lower frequency part is only present in the calculated spectra of structures of negligible populations, such as $W 11-4, W 11-5$ and $W 11-8$. For $n=9$, relative free energies at $130 \mathrm{~K}$ (see Table S2) indicate large populations of W9-1 and W9-2, together with minor contributions from W9-3, W9-5 and W9-6. As for $n=11$, there is good agreement with the experimental spectrum, except for the low frequency region.

Such discrepancies are not unexpected, because the harmonic approximation is known to be unable to account for strong interactions generating very large red shifts, as is the case here. In order to investigate the extent to which anharmonicity is involved, vibrational spectra were computed in the GVPT2 approximation (see Fig. $S 1$ for $n=9$ ). The results show that the AADD water molecule in W9-2 undergoes strong anharmonic shifts of its antisymmetric and symmetric stretching vibrations, from 3407 and 3473, to 3066 and $3204 \mathrm{~cm}^{-1}$, respectively. Analogous shifts are computed for W12-1, however, the anharmonic intensity is smaller than the harmonic, whereas the reverse is true for W9-2. These results compare favorably with the experimentally observed bands, significant for $\mathrm{n}=9$ and small to negligible for $\mathrm{n}=12$.

There has been recent discussion over the general type of lowenergy structures in this size range. In particular, structures with all molecules in the first hydration sphere have been invoked. For $\mathrm{n}=9$, the corresponding structure is W9-7. In addition to having an 


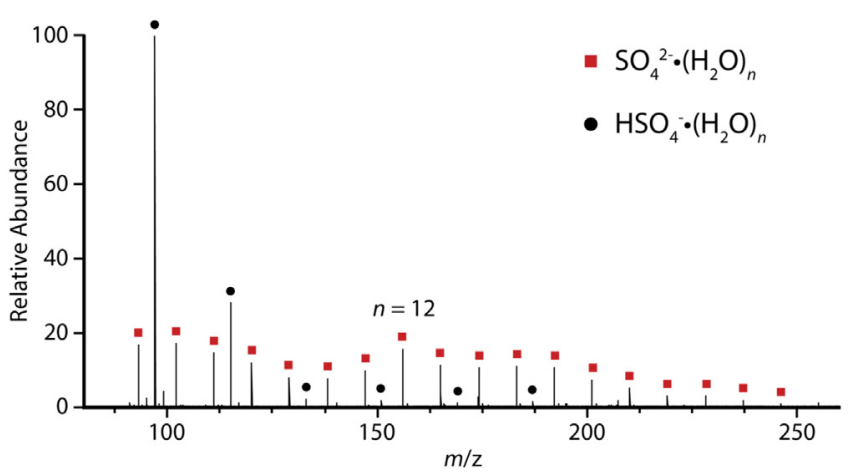

Fig. 8. Electrospray ionization mass spectrum of hydrated $\mathrm{SO}_{4}{ }^{2-} \cdot \mathrm{n}=12$ is marked by an increased abundance relative to neighboring cluster sizes.

unfavorable energy, comparison of its computed spectrum to the experimental one in Fig. 3 makes it clear that this structure cannot be significantly populated in the present experiments.

\subsection{Water dissociation energies of $\mathrm{SO}_{4}{ }^{2-}\left(\mathrm{H}_{2} \mathrm{O}\right)_{12}$ and $\mathrm{SO}_{4}{ }^{2-}\left(\mathrm{H}_{2} \mathrm{O}\right)_{13}$}

An ESI mass spectrum of hydrated sulfate ions is shown in Fig. 8. In the range between $\mathrm{n}=9$ and $14, \mathrm{SO}_{4}{ }^{2-}\left(\mathrm{H}_{2} \mathrm{O}\right)_{12}$ is the most abundant species. The difference with $\mathrm{SO}_{4}{ }^{2-}\left(\mathrm{H}_{2} \mathrm{O}\right)_{11}$ is especially strong. Two reasons can be invoked to account for these abundance variations: a particularly stable form of $\mathrm{SO}_{4}{ }^{2-}\left(\mathrm{H}_{2} \mathrm{O}\right)_{12}$ with a large water evaporation energy, or an easy dissociation from $\mathrm{SO}_{4}{ }^{2-}\left(\mathrm{H}_{2} \mathrm{O}\right)_{13}$, or a combination of both. Our results indicate that $\mathrm{SO}_{4}{ }^{2-}\left(\mathrm{H}_{2} \mathrm{O}\right)_{12}$ plays a pivotal role in this respect, with a highly compact and symmetric structure, whereas $\mathrm{SO}_{4}{ }^{2-}\left(\mathrm{H}_{2} \mathrm{O}\right)_{11}$ and $\mathrm{SO}_{4}{ }^{2-}\left(\mathrm{H}_{2} \mathrm{O}\right)_{13}$ are best described as the same structure with one less and one more water molecule, respectively. Removal of $\mathrm{H}_{2} \mathrm{O}$ from $\mathrm{SO}_{4}{ }^{2-}\left(\mathrm{H}_{2} \mathrm{O}\right)_{12}$ leaves $\mathrm{SO}_{4}{ }^{2-}\left(\mathrm{H}_{2} \mathrm{O}\right)_{11}$ with a hole and a weakly interacting $\mathrm{O}-\mathrm{H}$ bond. This is expected to correspond to a large dissociation energy. $\mathrm{SO}_{4}{ }^{2-}\left(\mathrm{H}_{2} \mathrm{O}\right)_{13}$ is best described as a $\mathrm{SO}_{4}{ }^{2-}\left(\mathrm{H}_{2} \mathrm{O}\right)_{12}$ core to which a water molecule can be added onto several possible sites, with limited specificity. Thus it is not surprising that the water dissociation energy from $\mathrm{SO}_{4}{ }^{2-}\left(\mathrm{H}_{2} \mathrm{O}\right)_{13}$, computed to be $47 \mathrm{~kJ} \mathrm{~mol}^{-1}$ at $130 \mathrm{~K}$ (using harmonic frequencies), is much smaller than the value of $59 \mathrm{~kJ} \mathrm{~mol}^{-1}$ computed for $\mathrm{SO}_{4}{ }^{2-}\left(\mathrm{H}_{2} \mathrm{O}\right)_{12}$. The high calculated water dissociation energy for $\mathrm{n}=12$ is consistent with previous BIRD measurments [21] which indicate that this cluster is especially stable compared to neighboring cluster sizes.

\section{Conclusions}

Experimental IRPD spectra are reported for $\mathrm{SO}_{4}{ }^{2-}\left(\mathrm{H}_{2} \mathrm{O}\right)_{n}$, $\mathrm{n}=9-13$, and are compared to computed IR spectra for $\mathrm{n}=9$ and 11-13. The spectra for the various sizes have many common features, which are attributable to water molecules in the first hydration sphere of the sulfate ion. Stretching frequencies are generally lower for $\mathrm{O}-\mathrm{H}$ bonds interacting with the sulfate than for those interacting with another water molecule. Some distinct differences can be traced to the number of water molecules in the second sphere, growing with cluster size, from 0 or 1 for $n=9,2-3$ for $n=11$, and $3-4$ for $n=12$ and 13 . The higher frequencies generally associated with $\mathrm{O}-\mathrm{H}$ stretches that are remote from the sulfate account for the larger intensities recorded in the $3350-3650 \mathrm{~cm}^{-1}$ range for clusters of larger sizes. Whereas most water molecules have ADD coordination, there are cases of DD coordination to the sulfate, and also some AADD water molecules, both having strongly frustrated hydrogen bonds generating extensions in the blue region of the spectrum. On the other hand, when an AADD molecule inter- acts with the sulfate, this particular $\mathrm{O}-\mathrm{H}$ stretching motion appears especially far to the red. It is expected for larger sizes that when all sulfate oxygens are 3-coordinated, and when the fraction of AADD molecules grows larger, especially in the first hydration sphere, the main intensity massif will continue shifting significantly.

The highly compact structure of $\mathrm{SO}_{4}{ }^{2-}\left(\mathrm{H}_{2} \mathrm{O}\right)_{12}$ leads to a high water dissociation energy to form $\mathrm{SO}_{4}{ }^{2-}\left(\mathrm{H}_{2} \mathrm{O}\right)_{11}$, and a small association energy to form $\mathrm{SO}_{4}{ }^{2-}\left(\mathrm{H}_{2} \mathrm{O}\right)_{13}$. As a result, the abundance of $\mathrm{SO}_{4}{ }^{2-}\left(\mathrm{H}_{2} \mathrm{O}\right)_{12}$ is larger than both neighboring cluster sizes. Other "magic numbers" exist for larger sulfate hydrates, calling for further work on sulfate ion hydration. This is currently underway using a different computational strategy to describe temperature effects and the complexity of the structural manifold $[35,36]$.

\section{Acknowledgments}

Florian Thaunay gratefully acknowledges a doctoral fellowship provided by Ecole polytechnique. Ayah Hassan was also supported by E.P., through the international internship program. This material is based upon work supported by the National Science Foundation under CHE-1609866.

\section{Appendix A. Supplementary data}

Supplementary data associated with this article can be found, in the online version, at http://dx.doi.org/10.1016/j.ijms.2017.01.005.

\section{References}

[1] B.J. Finlayson-Pitts, J.N. Pitts Jr., Chemistry of the Upper and Lower Atmosphere - theory, Experiments and Applications, Academic Press, San Diego, 2000

[2] S. Twomey, Atmospheric Aerosols, Elsevier, New York, 1977.

[3] A. Laaksonen, M. Kulmala, T. Berndt, F. Stratmann, S. Mikkonen, A. Ruuskanen, K.E.J. Lehtinen, M. Dal Maso, P. Aalto, T. Petäjä, et al., Atmos. Chem. Phys. 8 (2008) 7255 .

[4] V. Ramanathan, P.J. Crutzen, J.T. Kiehl, D. Rosenfeld, Science 294 (2001) 2119.

[5] J.T. O’Brien, J.S. Prell, M.F. Bush, E.R. Williams, J. Am. Chem. Soc. 132 (2010) $8248-8249$.

[6] J.T. O’Brien, E.R. Williams, J. Am. Chem. Soc. 134 (2012) 10228-10236.

[7] X.B. Wang, J.B. Nicholas, L.S. Wang, J. Chem. Phys. 113 (2000) 10837

[8] A.T. Blades, P. Kebarle, J. Am. Chem. Soc. 116 (1994) 10761-10766.

[9] C.C. Pye, W.W. Rudolph, J. Phys. Chem. A 105 (2001) 905-912.

[10] C.G. Zhan, F. Zheng, D.A. Dixon, J. Chem. Phys. 119 (2003) 781-793.

[11] B. Gao, Z.F. Liu, J. Chem. Phys. 121 (2004) 8299-8306.

[12] B. Gao, Z. Liu, J. Chem. Phys. 123 (2005) 224302.

[13] Y. Miller, G.M. Chaban, J. Zhou, K.R. Asmis, D.M. Neumark, R.B. Gerber, J. Chem. Phys. 127 (2007) 094305.

[14] M.F. Bush, R.J. Saykally, E.R. Williams, J. Am. Chem. Soc. 129 (2007) 2220-2221.

[15] X.B. Wang, A.P. Sergeeva, J. Yang, X.P. Xing, A.I. Boldyrev, L.S. Wang, J. Phys. Chem. A 113 (2009) 5567-5576.

[16] D.S. Lambrecht, G.N.I. Clark, T. Head-Gordon, M. Head-Gordon, J. Phys. Chem. A 115 (2011) 11438

[17] D.S. Lambrecht, L. McCaslin, S.S. Xantheas, E. Epifanovsky, M. Head-Gordon, Mol. Phys. 110 (2012) 2513.

[18] N. Mardirossian, D.S. Lambrecht, L. McCaslin, S.S. Xantheas, M. Head-Gordon, J. Chem. Theor. Comput. 9 (2013) 1368-1380.

[19] X.B. Wang, X. Yang, J.B. Nicholas, L.S. Wang, Science 294 (2001) 1322-1325.

[20] J. Zhou, G. Santambrogio, M. Brümmer, D.T. Moore, L. Wöste, G. Meijer, D.M. Neumark, K.R. Asmis, J. Chem. Phys. 125 (2006) 111102

[21] R.L. Wong, E.R. Williams, J. Phys. Chem. A 107 (2003) 10976-10983.

[22] A.T. Blades, J.S. Klassen, P. Kebarle, J. Am. Chem. Soc. 117 (1995) 10563.

[23] A.T. Blades, P. Kebarle, J. Phys. Chem. A 109 (2005) 8293-8298.

[24] F. Thaunay, C. Clavaguéra, G. Ohanessian, Phys. Chem. Chem. Phys. 17 (2015) 25935-25945.

[25] M.F. Bush, J.T. O’Brien, J.S. Prell, R.J. Saykally, E.R. Williams, J. Am. Chem. Soc. 129 (2007) 1612-1622.

[26] R.L. Wong, K. Paech, E.R. Williams, Int. J. Mass. Spectrom. 232 (2004) 59-66.

[27] Q. Wan, L. Spanu, G. Galli, J. Phys. Chem. B 116 (2012) 9460-9466.

[28] L.C. Smeeton, J.D. Farrell, M.T. Oakley, D.J. Wales, R.L. Johnston, J. Chem. Theor. Comput. 11 (2015) 2377-2384.

[29] A.A. Hagberg, D.A. Schult, P.J. Swart, Proceedings of the 7th Python in Science Conference, Pasadena, CA, USA, 2008, pp. 11-15.

[30] (a) C. Riplinger, B. Sandhoefer, A. Hansen, F. Neese, J. Chem. Phys. 139 (2013) 134101;

(b) M. Sparta, F. Neese, Chem. Soc. Rev. 43 (2014) 5032-5041. 
[31] J.W. Ponder, Tinker 6 - Software Tools for Molecular Design, 2010, Available at http://dasher.wustl.edu/tinker.

[32] M.J. Frisch, G.W. Trucks, H.B. Schlegel, G.E. Scuseria, M.A. Robb, J.R.

Cheeseman, G. Scalmani, V. Barone, B. Mennucci, G.A. Petersson, et al., Gaussian09, rev. D.01, Gaussian, Inc Wallingford CT, 2013.

[33] Orca version 3.0.3. F. Neese, WIREs Comput. Mol. Sci. 2012, 2, 73-78. Available at http://www.thch.uni-bonn.de/tc/orca/.
[34] E. Wenersson, P. Jungwirth, J. Chem. Theor. Comput. 6 (2010) 3233-3240.

[35] D. Semrouni, A. Sharma, J.-P. Dognon, G. Ohanessian, C. Clavaguéra, J. Chem. Theor. Comput. 10 (2014) 3190.

[36] C. Jana, C. Clavaguéra, G. Ohanessian, Theor. Chem. Acc. 135 (2016) 141-153. 